\title{
Correction to: Negatively or positively biased? Dependencies of teachers' judgments and expectations based on students' ethnic and social backgrounds
}

\section{Anita Tobisch $^{1}$ (D) Markus Dresel ${ }^{1}$}

Published online: 9 March 2020

(c) Springer Nature B.V. 2020

\section{Correction to: Soc Psychol Educ (2017) 20:731-752 \\ https://doi.org/10.1007/s11218-017-9392-z}

After publication of our article (Tobisch and Dresel 2017) it came to our attention that in the section " 2.2 The case of Germany", we omitted to mention that in an experimental study presented by Hoenig and Wenz (2013) names were used to manipulate and disentangle students' ethnic and social background. By this approach, they found effects of students' ethnic as well as social background on teachers' judgments. In the meantime, the study is also published (Wenz and Hoenig 2019).

\section{References}

Hoenig, K., \& Wenz, S. E. (2013). Ethnic and social class discrimination in education. Experimental evidence from Germany. Paper presented at the ASA 2013 annual meeting, New York, NY. https:// osf.io/9z538/.

Tobisch, A., \& Dresel, M. (2017). Negatively or positively biased? Dependencies of teachers' judgments and expectations based on students' ethnic and social backgrounds. Social Psychology of Education, 20, 731-752. https://doi.org/10.1007/s11218-017-9392-z.

Wenz, S. E., \& Hoenig, K. (2019). Ethnic and social class discrimination in education: Experimental evidence from Germany. Research in Social Stratification and Mobility. https://doi.org/10.1016/j. rssm.2019.100461.

Publisher's Note Springer Nature remains neutral with regard to jurisdictional claims in published maps and institutional affiliations.

The original article can be found online at https://doi.org/10.1007/s11218-017-9392-z.

Anita Tobisch

anita.tobisch@phil.uni-augsburg.de

1 Department of Psychology, University of Augsburg, Universitaetsstrasse 10, 86159 Augsburg, Germany 